\title{
District Health Service Management
}

\author{
Poudel SK*, Subedi S, Khadka S, Timilsina S, Sharma S, Roy SK, Gaire S, Poudel S, \\ Shrestha S, Jha V, Yadav V, Thapa Y \\ Final year MBBS, Gandaki Medical College \& Teaching Hospital
}

\section{Keywords}

District health system,

Regional health directorate,

Regional tuberculosis center

\section{Corresponding author}

${ }^{*}$ Dr. Suraj Kumar Poudel

Final year MBBS

Gandaki Medical College \& Teaching

Hospital, Pokhara, Nepal

Email: surajpgyz.113@gmail.com

\begin{abstract}
District Health System Management is a comprehensive study of the health system of the district as a unit of national health system. The report of District Health System Management has been prepared as per the MBBS 4th year (Third phase) curriculum of Tribhuvan University (TU), Institute of Medicine (IOM), Nepal after the field placement of our group in Gorkha and Kaski districts.
\end{abstract}

We prepared regional health directorate profile, regional tuberculosis center profile, district profile, district health profile of Kaski, hospital profile of Western Regional Hospital, Kaski, and critical analysis on human resources of the Aampipal hospital. We prepared five year plan on ICU services of Gorkha District Hospital and conducted epidemiological study on COPD in WRH, Pokhara.

The techniques used in this study were observation, interviews, interactions, participation, secondary data retrieval, analysis and presentation using specific tools and guidelines devised for the same.

The field practice proved to be a milestone in enabling the students to develop aptitude in the fields of management, administration and communication in different health set-ups of the country. It is in fact once-in-a lifetime opportunity for the medical students to imbibe the practicality of management skills at various levels.

\section{INTRODUCTION}

District health service management is a comprehensive study of the health system of the district as a unit of national health system. As per the curriculum for Bachelor of Medicine and Bachelor of Surgery (MBBS) program of Institute of Medicine (IOM), the Department of Community Medicine, Gandaki Medical College has been conducting the District Health System Management study for the $4^{\text {th }}$ year (Third phase) MBBS students. The field program aims to enable students to understand the type of work they are expected to perform in hospital of periphery as well as to acquire knowledge and skill in administration, management and supervision while working as a team member at district level.
The program includes theory classes on management and orientation classes at campus and placement of the students in three different districts along with on field supervisions in between. Since districts of Nepal are the most peripheral fully organized unit of local Government and administration, placement of students at the same places justifies the essence and objectives of the program. For the purpose, six different groups were placed at five different sites with the compulsion for each group to rotate at three sites within a period of six weeks. Among all groups, our group (F) spent two weeks each in the Western Regional Health Directorate, Western Regional hospital, Regional TB Center, DPHO, Kaski; Aampipal Community Hospital, Gorkha District Hospital and Gorkha District Public Health Office, Gorkha from 2 Poush 2074 to 12 Magh 2074. 


\section{GOAL}

The goal of the study was to acquire knowledge and skills in health system management, administration and planning while working as a team in the allocated districts.

\section{OBJECTIVES}

\section{General objective}

To understand the health care delivery system in the district so as to attain knowledge and skills in different aspects of management

\section{Specific objectives}

1. To get acquainted with the existing health care delivery system in the district in terms of infrastructure, human resources, financial status, management, accessibility and availability

2. To acquire knowledge regarding management, activities and roles of various health institutions of a district.

3. To develop knowledge and skills to review and prepare district profile and district health profile

4. To understand all managerial aspects of a hospital and hence prepare a hospital profile

5. To develop knowledge and skills to prepare epidemiological study in selected health problem

6. To develop knowledge and skills to prepare five year plan on health management issue or health program

7. To develop knowledge and skills to critically analyze specific health management issue

Table 1: Study site

\begin{tabular}{|c|c|}
\hline District & Placement \\
\hline Kaski, Pokhara & $\begin{array}{l}\text { Western Regional Health Directorate, } \\
\text { Western Regional Hospital, } \\
\text { Regional TB center, } \\
\text { District Public Health Office (DPHO) }\end{array}$ \\
\hline Aampipal, Gorkha & Aampipal Community Hospital \\
\hline Haramtari, Gorkha & District Public Health Office \\
\hline
\end{tabular}

\section{Study duration}

A total of six weeks were allocated for the study. Two weeks were spent in each of the study districts to fulfill our objectives.

We prepared regional health directorate profile, regional tuberculosis center profile, district profile, district health profile of Kaski district, hospital profile of Western Regional Hospital, Kaski, critical analysis on human resources of the Aampipal hospital. We prepared five year plan on ICU services of Gorkha district hospital and conducted epidemiological study on COPD in Western regional hospital.

\section{Study techniques and tools}

The techniques used in this study were observation, interviews and interactions, participation, secondary data retrieval and analysis, document review and presentations. Observations regarding the infrastructure and management aspects were based on criteria such as adequacy, appropriateness, utilization, effectiveness, constraints and weaknesses.

We also participated in various events such as meetings, clinical rounds in the hospital, training programs and free health camp. Wherever relevant and necessary, secondary data were retrieved and analyzed from record/statistical sections or from the recording registers at different departments of the concerned institution. Prepared guidelines and semi-structured questionnaires were used during those interviews (for DPHOr, MS, administrative in-charge, accounts in-charge, hospital staff, HP and PHC in-charge). A presentation was made at all those three hospitals in front of all the concerned people by our group at the end of each posting.

\section{Data Collection}

Almost all of the data used in this study were secondary. The sources of data were annual report, records from different sections of DHO/DPHO and hospitals, relevant national and local publications as well as pertinent information from journals. The data collected were both qualitative and quantitative.

\section{Ethical considerations}

We submitted the official letters from campus to the institutions. Before approaching any personnel for interview or discussion, we explained the objectives of the study and took verbal consent. An informed verbal consent was taken with every patient or patient parties who were interviewed. However written consent was not 
taken. Confidentiality was maintained as far as possible.

\section{DISTRICT HEALTH PROFILE}

Kaski district lies in Gandaki zone of Western Development Region. The district its district headquarters, covers an area of 2,01,700 hector and has a population of 4,92,098. It consists of three constituencies, one metropolitan city and four Gaupalika and provides health services through two hospitals, four PHCC, and 44 HPs. The district runs different preventive, promotive and curative health programs like expanded program on immunization, control of infectious diseases, national program, family health program and maternal and child health programs. Besides this, district health system has also been able to provide effective health education and the awareness among the public.

\section{HOSPITAL PROFILE}

Western Regional Hospital located at Ramghat of Kaski is the regional hospital of Western Development Region. It was established in 2012 B.S. and named as "Soldiers Board Hospital" strongly initiated by Major Bir Singh Gurung and his friends. It also provides health services to the poor, rural, Dalit and other marginalized people. It is a 500 bedded hospital. Being the Regional Hospital, whole Western Region is catchment area with patients mainly from the Kaski, Tanahun, Syangja, Parbat and Baglung districts visit here. It provides 24 hours emergency service, pharmacy with adequate medicine, X-ray service, USG service, lab service and other preventive and promotive services.

\section{REGIONAL TUBERCULOSIS CENTRE PROFILE}

We were posted to RTC for one day where we conducted a study about tuberculosis profile of Western Development Region and we found out that there are 93 microscopy centres, 26 urban DOTS, 4 DR treatment centre, 14 DR treatment sub-centres, four Gene Xpert centres and one culture service (RTC) in 16 districts. In fiscal year $2072 / 73$ total all forms of TB cases notified was 5635 , case notification rate was 109 per 1,00,000 population, 2572 new PBC cases, 992 newPCD cases, 1482 new EP cases. Total slides examined were 5300 ; total slide positivity rate was $8.06 \%, 73 \%$ casefinding rate, $90 \%$ sputum conversion rate, $88 \%$ cure rate, $90 \%$ treatment success rate, $4.5 \%$ death rate, $1.3 \%$ loss to follow up and $1.4 \%$ failure rate.

\section{REGIONAL HEALTH DIRECTORATE}

We were posted in RHD for four days. Western regional health directorate (WRHD) looks health system of all Western Development Region which was established in 2941 B.S. The functions of WRHD are to develop annual work plan, implement national policy, regional level programs, conduct monitoring and supervision of district level program, monitor online based monthly district report, maintain personal record of the staff within the region, provide incentive and penalize sixth and below level staff, monitor and control the financial transaction in the district level etc. Main health activities within the region are child health (immunization, nutrition, CBIMNCI), family health (safe motherhood, family planning, FCHV, PHCORC), disease control program (TB, leprosy, HIV-AIDS, epidemic outbreak and disaster management), training, health education, special health, curative services health promotion for non-communicable diseases.

\section{CRITICAL ANALYSIS}

We did critical analysis on human resources in Aamipipal Hospital. Then reason behind choosing this topic was that among 17 sanctioned posts from GO, only 11 were fulfilled and geographical location of this hospital was very challenging.

\section{FIVE YEAR PLAN}

In Gorkha District Hospital, there are large number of referral cases and large number of complications. To reduce the large number of referral cases and complications we made five year plan to establish and start ICU service. We planned different activities to achieve our target within budget five crore twenty six lakh seventy four thousands.

\section{EPIDEMIOLOGICAL STUDY}

Epidemiological study is done in COPD in Western Regional Hospital as it is one of the most common cause of hospital admission in Nepal. COPD is a respiratory disease. It is clinically characterized by cough, sputum production and exertional dyspnea. It is the number one cause mortality and number five cause of morbidity as per the Annual Report of Western Regional Hospital, 2073/74 B.S. reliable data was available and COPD being a non-communicable disease is adding misery along with communicable disease in our country.

\section{CONCLUSIONS}

The field practice proved to be a milestone in enabling the 
students to develop aptitude in the fields of management, administration and communication in different health set-ups of the country. It is infact once-in-a life-time opportunity for the medical students to imbibe the practicality of management skills at various levels.

1. Learned about the organization and functioning of district health system

2. We came to know the role and importance of peripheral health institutions and peripheral health care providers in promoting national health

3. Learned to identify the problems, their prioritization and carrying out studies to suggest feasible solution

4. Gained skill to conduct critical analysis and formulating a five year plan for a pertinent problem in the district

5. Built skill and confidence on interacting with stakeholders, local authorities and general public

6. Learned that besides clinical expertise, doctors should have managerial and administrative skills as well as leadership.

\section{Acknowledgement}

It is our immense pleasure to acknowledge and express our sincere admiration and gratitude to all thse individuals and institutions for their invaluable prop up to bring about our all-inclusive district health system management study to make it productive and practical. We would like to reimburse appreciation to our Gandaki
Medical College \& Teaching Hospital for providing us an opportunity to renovate our conjectural knowledge into practical understanding and skills needed to become a competent and proficient health care provider. We convey our respect and gratitude to all those, who directly or indirectly helped us in this field process.

\section{REFERENCES}

1. Park's Text Book of Preventive and Social Medicine, $22^{\text {nd }}$ edition

2. Davidson's Principles and Practice of Medicine, $23 \mathrm{rd}$ edition

3. DoHS, MoHP, Annual Report 2071/72 B.S.

4. DoHS, MoHP, Annual Report 2072/73 B.S.

5. DoHS, MoHP, Annual Report 2073/74 B.S. 